\section{In Defense of Powerpoint}

Neville Holmes, University of Tasmania
The first machine I remember being used for indirect presentation, apart from the movie projector, was the epidiascope, a rather cumbersome machine that projected by reflected light. The development of robust transparent foolscap sheets made the overhead projector popular, although it could also be used with transparent scrolls. Presenters also occasionally used 35-mm photographic slides, particularly at conferences, but the projectors needed an operator and thus

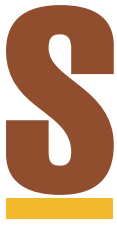

ome minor computing issues become major when repeatedly made public. The denigration of PowerPoint is such an issue, one that, like influenza, seems to come in seasonal waves.

The most recent wave started in the US as "PowerPoint Is Evil" (Wired, Sept. 2003; www.wired.com/wired/ archive/11.09/ppt2.html), spread to Australia as "Death by Slides" (Financial Review, 15 Nov. 2003; http://afr. com/articles/2003/11/14/1068674378 566.html), to the UK as "How PowerPoint Can Fatally Weaken Your Argument" (The Observer, 21 Dec. 2003; http://observer.guardian.co.uk/business/ story/0,6903,1110963,00.html), and back to the US as "Does PowerPoint Make Us Stupid?" (CNN, 30 Dec. 2003; www.cnn.com/2003/TECH/ptech/12/ 30/byrne.powerpoint.ap/). Further, a Non Sequitur cartoon this past April 29th showed a fully equipped Environmental Protection Agency squad storming triumphantly into a PowerPoint presentation.

This kind of story is not a joke. Although the authors of such post hoc arguments show occasional appreciation that the user should bear a little of the blame, they convey the overall impression that vile PowerPoint corrupts minds.

Yet it is their argument that's corrupt. PowerPoint is no more responsible for bad presentations than chainsaws are responsible for the clear-felling of oldgrowth forests. Technology is not itself responsible for the uses to which it is

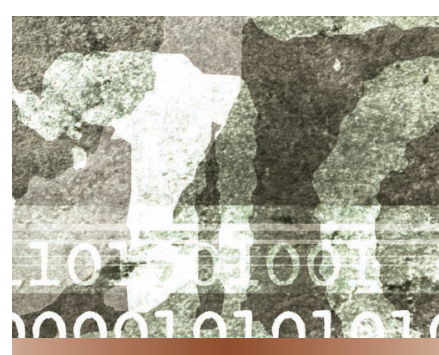

Professionals, not the software packages they use, are responsible for the presentations they make. put - technology's users must shoulder the blame.

Computing professionals who blame their machinery for their failures set a bad example for computer users already prone to using the computer as a scapegoat. Countering silly arguments about PowerPoint requires a full appreciation of presentation technology and of the uses to which it might be put. PowerPoint is just presentation technology's latest iteration and will eventually be replaced by something else.

\section{HISTORY LESSON}

Presentation technology first took a direct form. In Europe more than two millennia ago, presenters developed mnemonic techniques. For centuries, early books served only as a reference for presentations, the idea of reading silently being considered strange when first introduced.

Later, chalk and blackboards served as standard equipment in classrooms, with fancy blackboards being used in lecture rooms to record up to an hour or two of lecturing. Then came felt-tip or marker pens, flip charts, and the whiteboard. were rather "accident prone."

In the early 1970s, the availability of television sets brought computers into use for presentations. The first such machine I used-the 5100, IBM's second-generation personal computerhad a video socket at the back for use in connecting it by coaxial cable to a classroom TV. Later versions of the PC required more complex connections to display the panels that replaced the traditional transparencies sitting atop the overhead projector. Nowadays, PCs usually are connected to more powerful machines that double as video projectors.

As technology has advanced and the market expanded, developers have crafted a great variety of software. Early on, I found that I could easily use a debug script for DOS to place text anywhere I wanted on the screen, and I used batch files to put together and control presentations overall. I only switched to PowerPoint, which I found very difficult to make do what I wanted, when projectors could no longer be relied on to properly project 40-column DOS screens.

Continued on page 98 
The Profession

Continued from page 100

\section{USES}

Although presentations take many forms, they all combine three independent motivations, much as hues can be depicted as located within a color triangle according to their three basic components. Presentations can be used to

- convey information,

- collect information, and

- persuade an audience.

Currently, presenters most neglect the persuasive aspect, yet in olden times, knowledge of rhetorical principles was considered one of a classical education's more important benefits. The persuasive aspect is also the most significant for professionals, who must use facts and reasoning to help their clients and audiences make good decisions.

\section{Informing}

Education at all levels focuses in part on getting facts and ideas across to people. The professional issue involves determining what combination of technology and technique will do this best. Some teachers see PowerPoint as a splendid tool to help them convey ideas. Others prefer to use browser-driven HTML.

With the digital technology now available, we must ask if face-to-face presentation offers the best way to inform students. In the classroom at least, students learn better by doing than by merely listening or reading. I still remember a time early in my schooling when I spent hours and hours writing answers to sums on a slate. Thanks to this instruction, I can still sometimes astonish young shop assistants by giving them the correct sum long before their cash register tells them what the total is.

Our digital technology would be better used in the classroom by administering drill and practice as a foundation for literacy and numeracy so that teachers can concentrate on the more important job of inculcating and encouraging social capability, which they must do personally. Using computer-based academic gaming to create social situations could greatly help them in accomplishing this task.

But none of this involves PowerPoint. PowerPoint does, however, reign supreme at conferences-although conference presenters who merely recapitulate the contents of their paper place themselves in danger of putting their audience to sleep, particularly straight after lunch. A more effective approach uses the presentation to persuade the majority of the audience to actually read the paper, then devotes the question time to those few who have already read it. All of which puts conference presentations much more in the third class: persuasion.

\section{Some teachers see PowerPoint as a splendid tool to help them convey ideas.}

\section{Gathering data}

Presentations are given in personwhich means a successful presentation must be interactive. A good presenter will maintain eye contact and will, even in the absence of questions from his listeners, pick up their reactions and modify the presentation accordingly. A canned presentation, however, is hard to modify, whatever the software used. The more intricate the data, the harder the modification.

Many computing professionals focus on data gathering, which can often be done most effectively by taking a group of key informants away from their dayto-day activities to quiz them. These sessions need skilled management. The lead computing professional will typically start off with a presentation that gradually merges into a controlled group discussion. PowerPoint would be inappropriate here.

Although many professionals now prefer using electronic whiteboards in brainstorming and similar activities, I find it difficult to believe that the tra- ditional marker pen and flip chart approach wouldn't be better. The atmosphere in a room with scribbled flip charts hung up around the walls, with new charts being added, old ones being revised and re-sorted, and people moving around and discussing them, can be exhilarating and highly productive.

\section{Persuading}

The most important events in a computing professional's career involve the formal presentations given to persuade clients to accept a proposal or the results of work done. Here PowerPoint comes into its own.

Although some data must be shown, the focus stays on the presenter, not the PowerPoint slides. The slides should be as simple and undistracting as possible. Presenters need two kinds of slides for persuasive presentations: bulletpoint slides and data slides.

Long ago, I used my DOS batch files with one overhead projector for the bullet points and used transparencies on another overhead projector for the data slides, with a screen for each. This proved more effective than would using PowerPoint on a single projector today.

Data slides must be simplified so that their meaning becomes apparent only as the presenter explains them. Too much detail usually distracts audience members from the presenter and annoys them with difficult-to-read fine print. If presenters plan to show a lot of fancy graphics, they would probably be safer and better off simply showing them all from a videotape or DVD.

Bullet points-PowerPoint's most vilified aspect-are the most misunderstood of presentation techniques. As far as the audience is concerned, bullet points only serve to remind them of the presentation's general context. As far as the presenter is concerned, bullet points replace the mnemonic techniques handed down from the Greeks and the more recent prompt cards hidden in the hand of a formal debater.

Bullet-point slides should be as simple as possible, especially in content. 
This simplicity provides two important benefits: It lessens the distraction to the audience and supports spontaneity in the presenter-which is even more important than maintaining eye contact. Simple text lets presenters more easily lengthen or shorten the presentation to fit the time allowed, and it also lets them use larger letters.

Spontaneity can be achieved by rehearsing what might be said in respect to each bullet point so that when the point turns up in the presentation, the audience will see that the presenter is actively choosing what to say. The only thing that makes a worse impression on an audience than reciting from memory is reading from the screen - especially because the audience can read the text faster silently than the presenter can read it aloud. If a presenter must put up a long quotation, it should be a data slide that's easy for the audience to read.
A sans serif font is more legible onscreen than a serif one. I also suggest white letters on a black background.

or a computing professional, being able to give a good presentation is essential. Professional training should thus include instruction and practice in making presentations of all kinds, with the objective not so much to constrain the budding professional to any particular set of rules as to emphasize the importance of skill in presentations and purposeful thought in preparing for them.

Students should be trained in determining whether presentations are appropriate in different professional situations and in designing different kinds of presentations for different circumstances. In many situations, simple face-to-face discussions offer the best approach.
Presentations raise a much broader issue for all computing professionals, however. All too often, commentators and authors outside the professionand sadly some within - take an irrational stand on digital technology, blaming it for all kinds of social and economic ills. The condemnation of PowerPoint is only an obvious example. We must be sensitive to errors of this kind in ourselves and loud in counteracting public errors of this kind in others.

Neville Holmes is an honorary research associate at the University of Tasmania's School of Computing. Contact himatneville.holmes@utas.edu.au. Details of citations in this essay, and links to further material, are at www. comp.utas.edu.au/users/nholmes/prfsn.
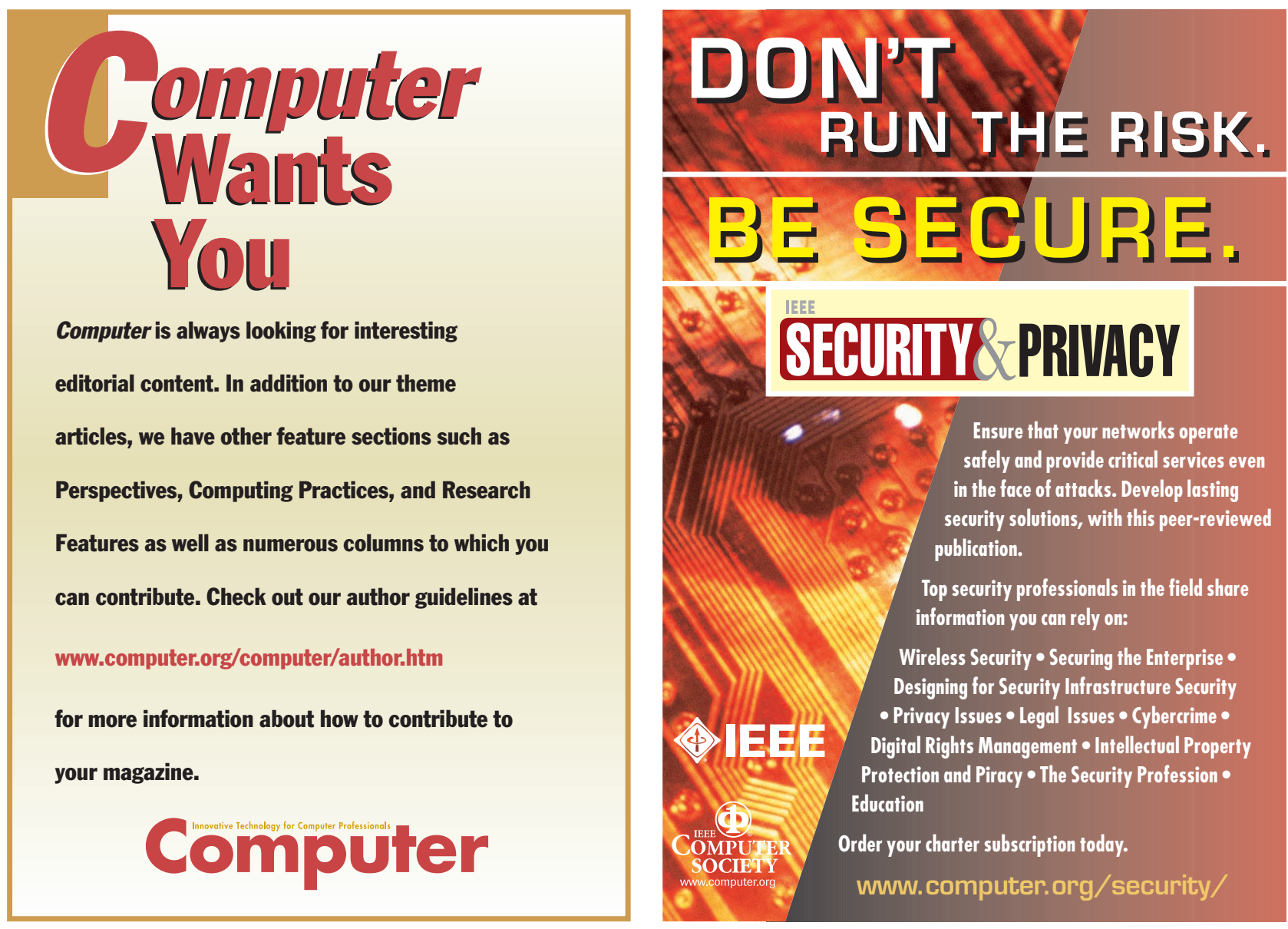